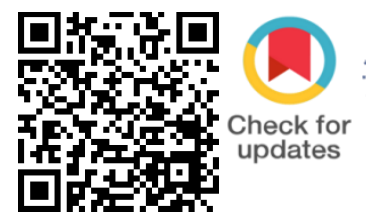

\title{
Voltage Stability Improvement with finest position of UPFC using GA \&PSO
}

\author{
Mahesh Kumarkorada $^{1}$ | R.S R Krishnam Naidu ${ }^{1}$ \\ ${ }^{1}$ Departmentof Electrical and Electronics Engineering, N S Raju Institute of Technology, Sontyam, A.P,
}

To Cite this Article

Mahesh Kumarkorada and R.S R Krishnam Naidu, "Voltage Stability Improvement with finest position of UPFC using GA \&PSO", International Journal for Modern Trends in Science and Technology, Vol. 07, Issue 03, March 2021, pp.: 280-285.

\section{Article Info}

Received on 21-February-2021, Revised on 17-March-2021, Accepted on 22-March-2021, Published on 26-March-2021.

\section{ABSTRACT}

Power system is a largely inter connected network, due to this interconnection some of the lines may get over loaded and voltage collapse will occur, hence these lines are called weak lines, this causes serious voltage instability at the particular lines of the power system. The improvement of stability will achieve by controlling the reactive power flow. The Flexible Alternating Current Transmission Systems (FACTS) devices have been proposed to effectively controlling the power flow in the lines and to regulate the bus voltages in electrical power systems, resulting in an increased power transfer capability, low system losses and improved stability.

In FACTS devices the Unified Power Flow Controller (UPFC) is one of the most promising device for power flow control. It can either simultaneously or selectively control both real and reactive flow and bus voltage. UPFC is a combination of shunt and series compensating devices. Optimal location of UPFC is determined based on Voltage Stability Index (VSI). GA and PSO techniques are used to set the parameters of UPFC [6]. The objective function formulated here is fitness function, which has to be maximized for net saving. The results obtained using PSO on IEEE 14 Bus is compared with that of results obtained using GA, to show the validity of the proposed techniques and for comparison purposes

KEYWORDS: Unified Power Flow Controller (UPFC), Genetic Algorithm (GA), Particle Swarm Optimization (PSO), and Voltage Stability Index (VSI).

\section{INTRODUCTION}

As the load increases, power utilities are looking for ways to maximize the utilization of their existing transmission systems, therefore controlling the power flow in the transmission lines is an important issue in planning and operating of power system. By using FACTS devices [1], it is also possible to control the phase angle, the voltage magnitude at chosen buses and/or line impedances of transmission system. Unified Power Flow Controller (UPFC) [3] is a versatile FACTS device which can independently or simultaneously control the active power, the reactive power, at the bus voltage to which it is connected. Following factors can be considered in the optimal installation and the optimal parameter of UPFC, the active power loss reduction, the stability margin improvement [2], the power transmission capacity increasing and power blackout prevention. Therefore conventional power flow algorithm should incorporate with UPFC considering one or all of the above mentioned factors. An algorithm is based on the steady state injection model of UPFC, a continuation power flow, and an optimal power flow was proposed in References and implemented an evolutionary programming approach to determine the optimal allocation of multi-type of FACTS devices [5]. This 
paper deals with the application of Particle Swarm Optimization (PSO) for finding the optimal location and the optimal parameters setting of the UPFC [6] with the consideration of total power loss reduction in the power system.

\section{SYSTEM MODEL}

To study the new control strategy for UPFC [7], a single-machine infinite-bus system is shown in the Fig. 1. The series converter injects a variable voltage source and the shunt converter injects a variable current. This modeling is helpful for understanding the effect of the UPFC on the power system in the steady state. The UPFC model can easily be incorporated in the steady state power flow model [8-9].

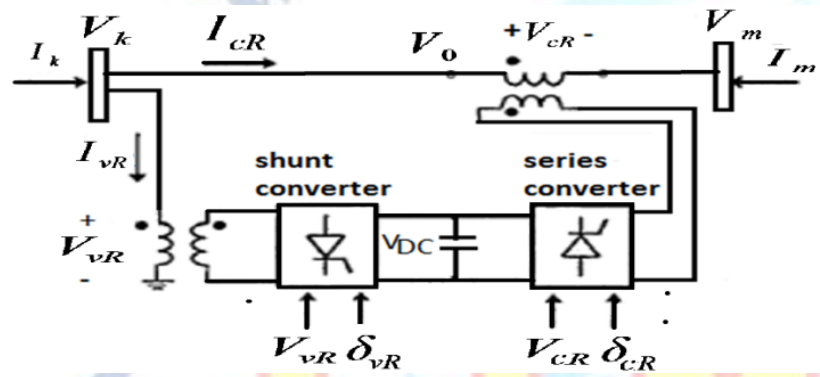

Figure.1. schematic diagram of UPFC

\section{MODELING OF UPFC}

The UPFC voltages are

$E_{v R}=V_{v R}\left(\cos \delta_{v R}+J \sin \delta_{v R}\right)$

Eq. 1

$E_{c R}=V_{c R}\left(\cos \delta_{c R}+J \sin \delta_{c R}\right)$

Eq. 2

Where VvR and $\delta v R$ are the controllable magnitude (VvRmin $\leq \mathrm{VVR} \leq \mathrm{VvRmax})$ and phase angle $(0 \leq \delta v R \leq 2 \pi)$ of the voltage source representing the shunt converter. The magnitude $\mathrm{VcR}$ and phase angle $\delta c R$ of the voltage source representing the series converter are controlled between limits (VcRmin $\leq \mathrm{VcR} \leq \mathrm{VcRmax})$ and $(0$ $\leq \delta c R \leq 2 \pi)$ respectively. The phase angle of the series- injected voltage determines the mode of power flow control. If $\delta c R$ is in phase with the nodal voltage angle $\theta \mathrm{k}$, the UPFC regulates the terminal voltage. If $\delta c R$ is in quadrature with respect to $\theta \mathrm{k}$, it controls active power flow, acting as a phase shifter. If $\delta c R$ is in quadrature with the line current angle then it controls active power flow, acting as a variable series compensator. At any other value of $\delta c R$, the UPFC operates as a combination of voltage regulator, variable series compensator, and phase shifter. The magnitude of the series-injected voltage determines the amount of power flow to be controlled.

\section{POWER FLOW MODEL}

The equivalent circuit consists of two ideal voltage sources representing the fundamental Fourier series component of the switched voltage waveforms at the AC converter terminals. As shown in the Fig. 2 Based on the equivalent circuit, the active and reactive power equations [10-11] are

\section{A. At bus $\mathrm{K}$}

$P_{k}=V_{m}^{2} G_{u k}+V_{k} V_{m}\left[G_{k n} \cos \left(\theta_{k}-\theta_{m}\right)+B_{k n} \sin \left(\theta_{k}-\theta_{m}\right)\right]+V_{k} V_{c k}\left[G_{k n} \cos \left(\theta_{k}-\delta_{c k}\right)+B_{k n} \sin \left(\theta_{k}-\delta_{c k}\right)\right]$ $+V_{k} V_{v R}\left[G_{\mathbb{R}} \cos \left(\theta_{k}-\delta_{c R}\right)+B_{v R} \sin \left(\theta_{k}-\delta_{c R}\right)\right]$

Eq. 3

$Q_{k}=-V_{k}^{2} B_{k k}+V_{k} V_{m}\left[G_{k n} \sin \left(\theta_{k}-\theta_{m}\right)-B_{k n} \cos \left(\theta_{k}-\theta_{m}\right)\right]+V_{k} V_{c k}\left[G_{k n} \sin \left(\theta_{k}-\delta_{c k}\right)-B_{k n} \cos \left(\theta_{k}-\delta_{c k}\right)\right]$ $+V_{k} V_{v \mathbb{R}}\left[G_{\text {vR }} \sin \left(\theta_{k}-\delta_{c R}\right)-B_{\text {vR }} \cos \left(\theta_{k}-\delta_{\text {vR }}\right)\right]$

Eq.4

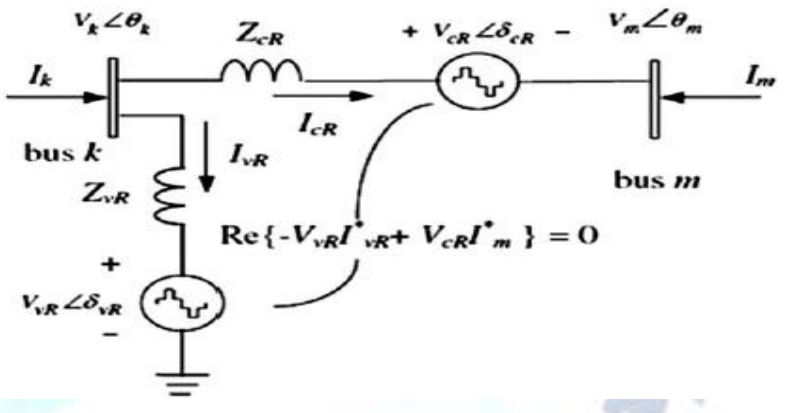

Fig.2. Unified Power Flow Controller equivalent circuit

At bus $m$

$P_{m}=V_{m}^{2} G_{m m}+V_{k} V_{m}\left[G_{m k} \cos \left(\theta_{m}-\theta_{k}\right)+B_{k n} \sin \left(\theta_{m}-\theta_{k}\right)\right]+V_{m} V_{c k}\left[G_{m n} \cos \left(\theta_{m}-\delta_{c k}\right)+B_{m m} \sin \left(\theta_{m}-\delta_{c k}\right)\right]$

Eq. 5

$Q_{m}=-V_{m}^{2} B_{m m}+V_{m} V_{k}\left[G_{m k} \cos \left(\theta_{m}-\theta_{k}\right)+B_{k n} \sin \left(\theta_{m}-\theta_{k}\right)\right]+V_{m} V_{c k}\left[G_{m m} \sin \left(\theta_{m}-\delta_{c k}\right)+B_{n m} \sin \left(\delta_{c k}-\theta_{m}\right)\right]$

Eq.6

Assuming loss-free converter valves, the active power supplied to the shunt converter, PvR, equals the active power demanded by the series converter, PcR, that is,

$$
P_{v R}+P_{c R}=0
$$

Furthermore, if the coupling transformers are assumed to contain no resistance then the active power at bus $\mathrm{k}$ matches the active power at bus $\mathrm{m}$, 
accordingly.

\section{UPFC Jacobian Equation}

The linearized power equations of UPFC are combined with the linearized system of equations corresponding to the rest of the network

$[J]=\left[\begin{array}{cc}H_{k k} & H_{k m} \\ H_{m k} & H_{m m} \\ J_{k k} & J_{k m} \\ J_{m k} & J_{m m} \\ H_{m k} & H_{m m} \\ J_{m k} & J_{m m} \\ H_{c R k}+H_{v R k} & H_{c k m}\end{array}\right.$

$H_{k v R}$
0
$L_{k v R}$
0
0
0
$N_{c R k}+N_{v R k}$

$\left.\begin{array}{cccc}N_{k m} & H_{k c R} & N_{k c R} & H_{c v R} \\ N_{m m} & H_{m v R} & N_{m v R} & 0 \\ L_{k m} & J_{k c R} & L_{k c R} & J_{k v R} \\ J_{m m} & J_{m c R} & L_{m c R} & 0 \\ N_{m m} & H_{m c R} & N_{m c R} & 0 \\ L_{m m} & J_{m c R} & L_{m c R} & 0 \\ N_{c R m} & H_{c R c R} & N_{c R c R} & H_{v R v R}\end{array}\right]$

Eq. 12

$[f(x)]=[J][\Delta X]$

Eq. 13

$[\Delta X]=\left[\Delta \theta_{k} \Delta \theta_{m} \frac{\Delta v_{V R}}{v_{V R}} \frac{\Delta v_{m}}{v_{m}} \Delta \theta_{c R} \frac{\Delta v_{c R}}{v_{c R}} \Delta \theta_{v R}\right]^{T}$

Eq. 14

$\Delta P_{b b}=$ is the power mismatch

$[\Delta X]=$ is the solution vector

$[J]=$ is the Jacobian matrix, $\mathrm{T}=$ represents transposition

\section{VOLTAGE STABILITY INDEX COMPUTATION}

Voltage stability index is the one which will gives the information about the of voltage collapse in week bus or also called overload buses, this technique is very much helpful to predict the operating condition of a power system. Voltage stability index (L-Index) developed by Kassel et al based on the power flow solution equation [12]. The L-index illustrates the stability of the entire system. The L-index is a measure for the estimation of system stability limit. A load flow result is obtained for a given system operating condition which is otherwise available from the output of an on line estimator.

Consider the power network consisting $n$ number of buses with 1,2, g generator buses, and $\mathrm{g}+1, \mathrm{n}$ remaining $(\mathrm{n}-\mathrm{g})$ buses. In this paper we have tested on the IEEE 14 bus system for a given operating condition, using the load flow results, the Voltage stability index 'L' can be calculated as

$$
L_{j}=\left|1-\sum_{i=1}^{g} F_{j i} \frac{V_{i}}{V_{j}}\right|
$$

Eq. 15

$\left[\begin{array}{c}V_{L} \\ I_{G}\end{array}\right]=\left[\begin{array}{ll}Z_{L L} & F_{L G} \\ K_{G L} & Y_{G G}\end{array}\right]\left[\begin{array}{l}I_{L} \\ V_{G}\end{array}\right]$

Eq.16

\section{V.EVOLUTIONARY OPTIMIZATION TECHNIQUES}

\section{Overview of GA}

One of the most famous meta-heuristic optimization algorithms is Genetic Algorithm (GA) [13] which is based on natural evolution and population. To reach the near global optimum solution Genetics are used. In each iteration of GA (generation), a new set of string (i.e. chromosomes) with improved fitness is produced using genetic operators (i.e. selection, crossover and mutation).

Selection Operator: it will give importance to better individuals, and pass them on their genes to the next generation. The best of each individual depends on its fitness.

By using objective function the Fitness may be determined or by a subjective judgment.

Crossover Operator: It is the Prime distinguished factor of Genetic algorithm from other optimization techniques. Using the selection operator two individuals are chosen from the population. A crossover site along the bit strings is randomly chosen. The values of the two strings are exchanged up to this point. If $\mathrm{S} 1=000000$ and s2 $=111111$ and the crossover point is 2 then $\mathrm{S} 1^{\prime}=110000$ and $\mathrm{s} 2{ }^{\prime}=001111$. The two new offspring created from this mating are put into the next generation of the population. This process is likely to create even better individuals by recombining portions of good individuals,

Mutation Operator: a portion of the new individuals will have some of their bits flipped with some low probability. The purpose of Mutation is to maintain diversity within the population and prevent premature convergence. Mutation alone induces a random walk through the search space; Mutation and selection (without crossover) create a parallel, hill-climbing algorithm.

Overview of PSO

First proposed by Kennedy and Eberhart in 1995, inspired by social behavior of bird flocking or fish schooling .Particle Swarm Optimization (PSO) is a population-based optimization method [14] it is 
also related, however, to evolutionary computation, and has ties to both genetic algorithms and evolutionary programming. The PSO as an optimization tool provides a population-based search procedure in which individuals called particles change their position (state) with time. In a PSO system, particles fly around in a multidimensional search space. During flight, each particle adjusts its position according to its own experience (This value is called Pbest), and according to the experience of a neighboring particle (This value is called Gbest), made use of the best position encountered by itself and its neighbor .After finding the best values the particles updated its velocity and position with the following equation:

$V_{1}^{k+1}=W V_{1}^{k}+C_{1} * \operatorname{rand} 1 *\left(P_{\text {bessi }}-S_{i}^{k}\right)+C_{2} * \operatorname{rand} 2 *\left(G_{\text {besti }}-S_{i}^{k}\right)$

Eq. 18

$S_{i}^{k+1}=S_{i}^{k}+V_{i}^{k+1}$

Eq. 19

$W=W_{\text {max }}-\left(\frac{W_{\text {max }}-W_{\text {min }}}{\text { iter }_{\text {max }}}\right) *$ iter

Eq. 20

\section{UPFC COST FUNCTION}

Using Siemens AG Database, cost function for UPFC is developed [15-16] as follows:

$$
\begin{aligned}
& C_{U P F C}=0.0003 S^{2}-0.2691 S+188.9 U S \$ / K V A R \\
& S=\left|Q_{2}-Q_{1}\right|
\end{aligned}
$$

Where, Operating range of UPFC is in MVAR

Q1= MVAR flow through the branch before placing FACTS device

$\mathrm{Q} 2=$ MVAR flow through the branch after placing FACTS device

The goal of optimization algorithm is to place FACTS devices in order to enhance voltage stability margin of power system considering cost function FACTS devices. So these devices should be place to prevent congestion in transmission lines and transformer and maintain bus voltages close to their reference.

\section{FITNESS FUNCTION}

The fitness function [16] can be expressed as bellow
$\operatorname{Max}, f=\left\{k_{e} * T *\left[T_{L}-U P F C T_{L}\right]-\alpha\left[C_{U P F C} * U P F C_{\text {rating }}\right]\right\}$

Eq.23

Where, Ke =Energy Cost,

$\mathrm{T}=$ Time Period (8760),

$\mathrm{T}_{\mathrm{L}}=$ Total power loss before UPFC placement,

$\alpha=$ Depreciation factor is 0.1

$C_{U P F C}=\mathrm{UPFC}$ Cost in $\mathrm{Rs} / \mathrm{KVAR}, U P F C_{\text {rating }}=$ Rating of the UPFC,

\section{SUMMARY OF PROPOSED TECHNIQUES

\begin{tabular}{|c|c|c|c|c|}
\hline \multicolumn{2}{|c|}{$t^{\text {Aspec }}$} & $\begin{array}{l}\text { Without } \\
\text { UPFC }\end{array}$ & UPFC+GA & $\begin{array}{l}\text { UPFC+PS } \\
0\end{array}$ \\
\hline \multirow{2}{*}{$\begin{array}{l}\text { PQ } \\
\text { Los } \\
\text { ses }\end{array}$} & $P_{L o}$ & $\begin{array}{l}14.02138 \\
\text { MW }\end{array}$ & $\begin{array}{l}13.960192 \\
M W\end{array}$ & 13.913635 \\
\hline & $\begin{array}{l}Q_{L} \\
\text { oss }\end{array}$ & $\begin{array}{l}54.425583 \\
\text { MVAR }\end{array}$ & $\begin{array}{l}51.935853 \\
\text { MVAR }\end{array}$ & $\begin{array}{l}51.702028 \\
\text { MVAR }\end{array}$ \\
\hline \multicolumn{2}{|c|}{$\begin{array}{l}\text { Total } \\
\text { Losses }\end{array}$} & $\begin{array}{l}54.2682 \mathrm{M} \\
\text { VA }\end{array}$ & $\begin{array}{l}53.7794 \mathrm{M} \\
\text { VA }\end{array}$ & $\begin{array}{l}53.5424 \mathrm{M} \\
\mathrm{VA}\end{array}$ \\
\hline \multicolumn{3}{|c|}{ proposed location } & $\begin{array}{l}\text { Between } \\
\text { bus10 \& } \\
11\end{array}$ & $\begin{array}{l}\text { Between } \\
\text { bus } 9 \text { and } \\
14\end{array}$ \\
\hline \multicolumn{3}{|c|}{$\begin{array}{l}\text { Investment Cost of } \\
\text { UPFC }\end{array}$} & $\begin{array}{l}7087.245 \\
\mathrm{Rs} / \mathrm{MW}\end{array}$ & $\begin{array}{l}7037.36 \\
\text { Rs/MW }\end{array}$ \\
\hline \multicolumn{3}{|c|}{ Fitness Value } & 70.803 & 68.90 \\
\hline \multicolumn{3}{|c|}{ Elapsed Time } & $\begin{array}{l}1.434176 \\
\min \end{array}$ & $\begin{array}{l}1.197035 \\
\min \end{array}$ \\
\hline
\end{tabular} FOR IEEE-14 BUS TEST SYSTEM:}

TABLE-I: Voltage Profile

\begin{tabular}{|l|l|l|l|}
\hline $\begin{array}{l}\text { Bus } \\
\text { numb } \\
\text { er }\end{array}$ & $\begin{array}{l}\text { Voltage(with } \\
\text { out UPFC) }\end{array}$ & $\begin{array}{l}\text { Voltage(G } \\
\text { A) }\end{array}$ & $\begin{array}{l}\text { Voltage(PS } \\
\text { O) }\end{array}$ \\
\hline 1 & 1.00000 & 1.00000 & 1.00000 \\
\hline 2 & 1.00000 & 1.00000 & 1.00000 \\
\hline 3 & 1.00000 & 1.00000 & 1.00000 \\
\hline 4 & 0.95205 & 1.00000 & 1.00000 \\
\hline 5 & 1.00000 & 1.00000 & 1.00000 \\
\hline 6 & 1.01514 & 1.02334 & 1.02333 \\
\hline 7 & 1.01814 & 1.03280 & 1.03284 \\
\hline 8 & 1.01814 & 1.02859 & 1.2871 \\
\hline 9 & 0.11419 & 1.00609 & 1.00624 \\
\hline 10 & 0.98815 & 1.00000 & 1.00000 \\
\hline 11 & 0.99194 & 1.05000 & 1.05000 \\
\hline 12 & 0.98516 & 1.03489 & 1.03594 \\
\hline 13 & 0.98482 & 1.03184 & 1.03182 \\
\hline 14 & 0.92566 & 0.95483 & 0.95494 \\
\hline
\end{tabular}

TABLE.2. Percentage Power Flows:

\begin{tabular}{|l|l|l|l|}
\hline $\begin{array}{l}\text { Line } \\
\text { number }\end{array}$ & $\begin{array}{l}\text { PQ Flows } \\
\text { (With out }\end{array}$ & $\begin{array}{l}\text { PQ } \\
\text { Flows }\end{array}$ & $\begin{array}{l}\text { PQ Flows } \\
\text { (PSO) }\end{array}$ \\
\hline
\end{tabular}




\begin{tabular}{|l|l|l|l|}
\hline & UPFC) & (GA) & \\
\hline 1 & 0.4999 & 0.9420 & 0.9423 \\
\hline 2 & 0.5491 & 0.5543 & 0.5536 \\
\hline 3 & 0.5700 & 0.5639 & 0.5643 \\
\hline 4 & 0.8824 & 0.8780 & 0.8747 \\
\hline 5 & 0.7294 & 0.7419 & 0.7401 \\
\hline 6 & 0.7312 & 0.7316 & 0.7301 \\
\hline 7 & 0.7224 & 0.5503 & 0.5639 \\
\hline 8 & 0.4680 & 0.5927 & 0.5424 \\
\hline 9 & 0.3865 & 0.4209 & 0.4210 \\
\hline 10 & 0.7967 & 0.9022 & 0.9069 \\
\hline 11 & 0.9462 & 0.9098 & 0.9096 \\
\hline 12 & 1.0594 & 0.9796 & 0.9891 \\
\hline 13 & 0.5314 & 0.3571 & 0.4052 \\
\hline 14 & 1.0435 & 0.9962 & 0.9793 \\
\hline 15 & 0.2957 & 0.0619 & 0.0619 \\
\hline 16 & 0.0595 & 0.0484 & 0.0519 \\
\hline 17 & 0.5879 & 0.6952 & 0.7025 \\
\hline 18 & 0.1922 & 0.1383 & 0.1479 \\
\hline 19 & 0.5281 & 0.4570 & 0.4690 \\
\hline 20 & 0.7856 & 0.9001 & 0.8832 \\
\hline
\end{tabular}

\section{RESULTS}

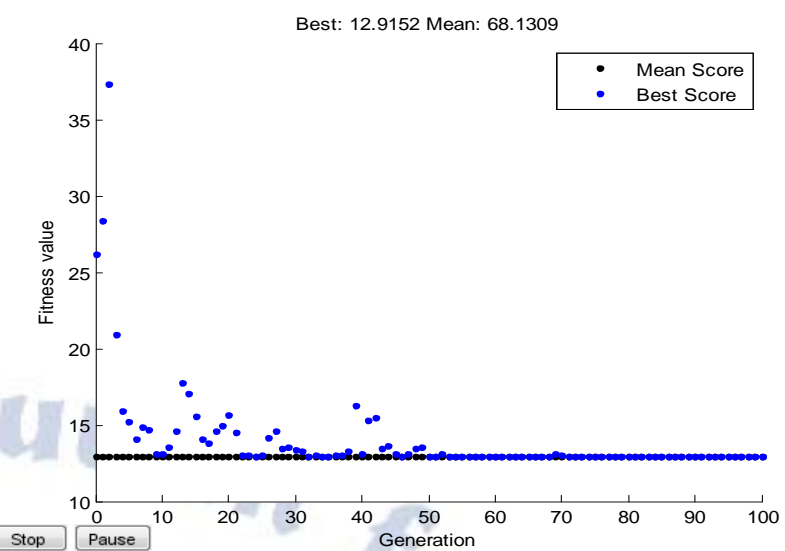

Fig.3. Plot between Objective Function of GA Vs Generations

Best: 12.916 Mean: 8925.66

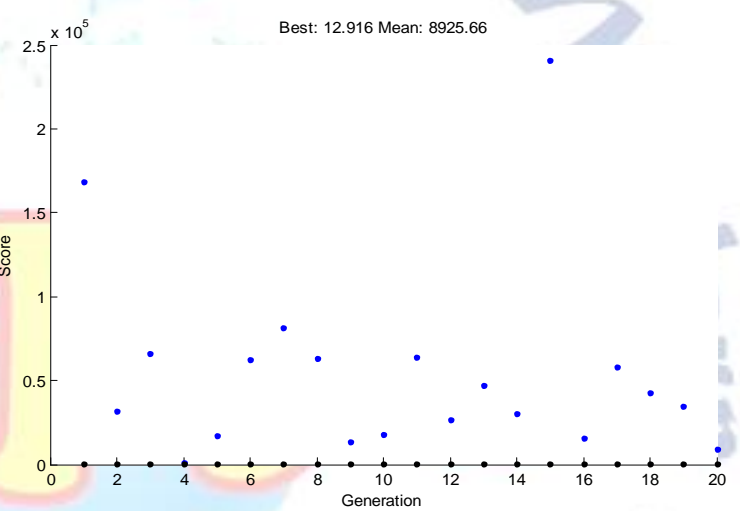

Fig.4. Plot between objective function of PSO Vs Generations

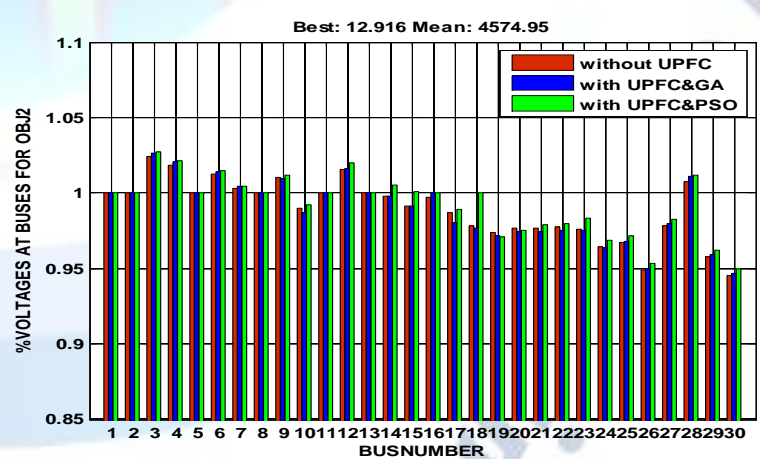

Fig.5. Voltage profile

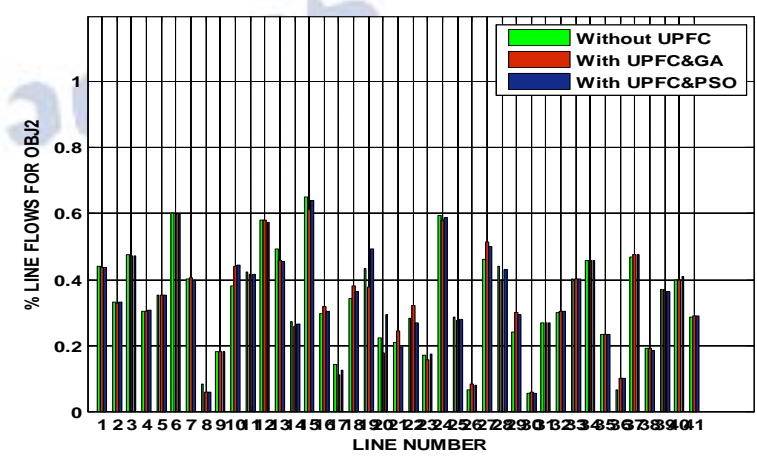

Fig.6. line flows 


\section{CONCLUSION}

In this paper, voltage stability index has been identified, which will enhance the power system stability. GA and PSO techniques are implemented for finding the optimal location for UPFC in the IEEE 14 Bus System. The obtained results show that PSO technique has superior features than GA, including high quality solution, stable convergence characteristics and good computation efficiency. Finally our results show that using UPFC in the optimal location with the optimal parameter settings can significantly improve the security of power system.

\section{REFERENCES}

[1] N G. Hingorani, and L. Gyugyi, "Understanding FACTS: Concepts and Technology of Flexible AC Transmission Systems", IEEE Press, New-York, 2000.

[2] M.K.Verma and S.C.Srivastava "Enhancement of voltage stability margin under contingencies using FACTS controllers" Proc. of the International Conference on Power System Operation in Deregulated Regime, IT-BHU, Varanasi (India), pp. 139-149, March 6-7, 2006

[3] L. Gyugyi, C. D.Schauder, S. L. Williams, T. R. Rittman, D.R.Torgerson, and A.Edris, "The unified power flow controller: a new approach to power transmission control," IEEE Trans. Power Del.

[4] S. Kannan, Shesha Jayaram, and M. M. A. Salama, "Real and Reactive power coordination for a Unified power flow controller," IEEE Trans. Power system, vol. 19, No. 3, pp. 1454-1462, Aug. 2004.

[5] H.A. Abdelsalam, G.E. M. Aly, M. Abdelkrim and K.M. Shebl, "Optimal location of the Unified Power Flow Controller in electrical power system," Proc. Of the Large Engineering Systems Conference on Power Engineering LESCOPE-2004, Westin Nova Scotian, pp. 41-46, July 28-30, 2004.

[6] H.I. Shaheen, G.I.Rashed, S.J.Cheng, "Application and comparison of computational intelligence techniques for optimal location and parameter setting of UPFC", Engineering Applications of Artificial Intelligence, 23, 203-216, 2010

[7] Z. Huang, Y. Ni, F. F. Wu, S. Chen, and B. Zhang, "Appication of unified power flow controller in interconnected power systems-modeling, interface, control strategy and case study," IEEE Trans. Power Syst, vol. 15, pp. 817-824, May 2000.

[8] H. Ambriz-Perez, E. Acha, C. R. Fuerte-Esquivel, and A. De la Torre, "Incorporation Of A UPFC Model In An Optimal Power Flow Using Newton's Method", IEE Proc.- Gener. Trans. Distrib., 145, (3), (1998), p. 336.

[9] Kalyan K. Sen, and Eric J. Stacey, "UPFC - Unified Power Flow Controller: Theory, Modeling and Applications", IEEE Trans. on Power Delivery, 13 (4) (1998), p. 1453.

[10] [10] A. Edris, A.S. Mehraban, M. Rahman, L. Gyugyi, S. Arabi, and T. Reitman, "Controlling The Flow Of Real And Reactive Power", IEEE Computer Applications In Power, January 1998, p. 20.

[11] R. J. Nelson, J. Bian, and S. L. Williams, "Transmission Series Power Flow Control", IEEE Trans. On Power Delivery, 10 (1) (1995), p. 504.

[12] Kessel P and Glavitsch H., "Estimating the voltage stability of a power system." IEEE Trans. Power Systems, vol. PWRD-1, no.3, pp. 346-352, Feb. 1992.

[13] D. E. Goldberg, Genetic Algorithms in Search, Optimization and Machine Learning, Addison-Wesley, 1989.

[14] S. Sutha, and N. Kamaraj," Optimal location of Multi type facts devices for multiple contingencies using particle swarm optimization," International Journal of Electrical
System Science and Engineering 1; www.waset.org winter 2008.

[15] Saravanan, M., et al., "Application of PSO technique for optimal location of FACST devices considering system loadability and cost of installation", in Power Engineering Conference, 716-721, 2005.

[16] J. Park, K. Lee, J. Shin, K. Y. Lee, "A Particle Swarm Optimization for Economic Dispatch with Nonsmooth Cost Function", IEEE Trans. on Power Systems, Vol. 20, No.1, Feb. 2005, pp. 34-42.

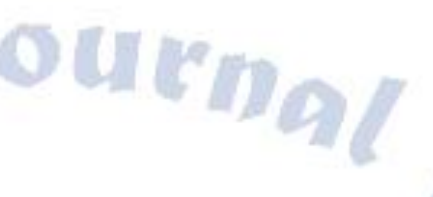

